\title{
CARACTERIZACIÓN BIOQUÍMICA, BIOLÓGICA Y MOLECULAR DEL FACTOR DIFUSOR PRESENTE EN EL VENENO DE LA SERPIENTE Bothrops atrox "JERGÓN"
}

\author{
Julio Delgadillo ${ }^{\mathrm{a}}$, Dan Vivas ${ }^{\mathrm{a}}$, Edith Rodríguez ${ }^{\mathrm{a}}$,Fanny Lazo ${ }^{\mathrm{a}}$, E. F. Sánchez ${ }^{\mathrm{b}}$ y \\ ArmandoYarlequéa*
}

\begin{abstract}
RESUMEN
La hialuronidasa del veneno de Bothrops atrox fue purificada y caracterizada. Se estudió el efecto de iones monovalentes y divalentes en su actividad catalítica, mostrando que el ion magnesio $(150 \mathrm{mM})$ incrementa la actividad en $40 \%$, mientras que la glicina lo inhibe en un $44 \%$. La enzima carece de actividad tóxica cuando es administrada en ratones albinos en ensayos de toxicidad, pero incrementa la acción hemorrágica del veneno total sobre la piel de estos animales. El antiveneno botrópico polivalente, Perú) fue capaz de reconocer componentes del veneno total de $B$. atrox, así como la enzima purificada, en ensayos de inmunodifusión. El cDNA que codifica para esta hialuronidasa se obtuvo a partir de mRNA extraído del veneno fresco, y secuenciado. El análisis de la secuencia de cDNA, de 2020 $\mathrm{pb}$, muestra que contiene un ORF de $1350 \mathrm{pb}$ que codifica para una pre-enzima de 449 aminoácidos, cuyo procesamiento, posiblemente, resulta en una enzima madura de 429 aminoácidos, masa molecular 50 kDa y pI de 9,19, indicando su naturaleza básica, y con 4 probables sitios de N-glicosilación (Asn103, Asn111, Asn153 y Asn357).
\end{abstract}

Palabras clave: veneno, serpiente, factor difusor, hialuronidasa, Bothrops atrox.

\section{SOME BIOCHEMICAL, BIOLOGICAL AND MOLECULAR CHARACTERISTICS OF THE DIFFUSION FACTOR FROM Bothrops atrox SNAKE VENOM}

\begin{abstract}
The hyaluronidase from Bothrops atrox venom was purified and characterized. The effect of monovalent and divalent ions on their catalytic activity was studied, showing that the magnesium ion $(150 \mathrm{mM})$ increases de activity in $40 \%$, while glycine inhibits it by $44 \%$. The enzyme lacks toxic activity, when administered in albino mice in toxicity tests, but increases the hemorrhagic action of the total venom on the skin of these animals. The polyvalent
\end{abstract}

${ }^{a}$ Lab. Biología Molecular - Facultad de Ciencias Biológicas - UNMSM - Perú

${ }^{\mathrm{b}}$ Centro de Investigación y Desenvolvimiento, FUNED - Brasil

*ayarleque48@gmail.com 
botropic antivenom, was able to recognize components of the total venom of $B$. atrox, as well as the purified enzyme, in immunodiffusion assays. The cDNA coding for hyaluronidase from the venom of $B$. atrox was obtained from mRNA extracted of the fresh venom, and sequenced. The analysis of the cDNA, of $2020 \mathrm{bp}$, shows that it contains an ORF of $1350 \mathrm{bp}$ that codes for a pre-enzyme of 449 amino acids, which probably is processing resulting in a mature enzyme of 429 amino acids, Molecular Weight of $50 \mathrm{kDa}$ and pI 9.19, indicating its basic nature, and with 4 probable N-glycosylation sites ( $\mathrm{Asn}^{103}, \mathrm{Asn}^{111}, \mathrm{Asn}^{153}$ and $\left.\mathrm{Asn}^{357}\right)$.

Key words: venom, snake, diffusion factor, hyaluronidase, Bothrops atrox.

\section{INTRODUCCIÓN}

El ácido hialurónico es un polisacárido multifuncional de alto peso molecular encontrado en todos los vertebrados; especialmente en los mamíferos, se encuentra en la matriz extracelular de tejido conectivo blando, la piel, cartílago y en el líquido sinovial1. Esta molécula participa en muchos procesos biológicos como la fecundación, reproducción, envejecimiento, comunicación celular, así como en la formación de tumores entre otros ${ }^{2}$.

Ante este abundante sustrato, la evolución dio origen a las hialuronidasas (E.C. 3.2.1.35), enzimas que se encuentran presentes en muchos organismos de diversos grupos (bacterias, insectos, arácnidos, reptiles, mamíferos, entre otros) con un mayor énfasis en los grupos de animales venenosos. Estas enzimas hidrolizan el ácido hialurónico (hialuronato) en el enlace $\beta$ (1-4) formado entre $\mathrm{N}$-acetilglucosamina y el ácido glucurónico ${ }^{3}$.

Las hialuronidasas son ubicuas en los venenos de serpientes, per se estas enzimas no son toxicas, pero participan en la difusión de los componentes tóxicos del veneno (metaloproteasas, serinoproteasas, fosfolipasas, entre otros) a razón de ello han recibido la denominación de "factores difusores". Pese a este rol primordial en el proceso de envenenamiento, aún se mantiene un limitado conocimiento sobre estas enzimas, principalmente por su inestabilidad, rápida degradación y bajo contenido en el veneno. Sin embargo, existen reportes de hialuronidasas aisladas del veneno de algunas especies ofídicas como: Agkistrodon contortrix contortrix ${ }^{4}$, Agkistrodon acutus ${ }^{5}$, Naja naja ${ }^{6}$ y Crotalus durissus terrrificus ${ }^{7}$.

En el Perú, esta enzima ha sido purificada sucesivamente de los venenos de Lachesis muta, Bothrops atrox ${ }^{7}$ y Bothrops brazili ${ }^{9}$ en los cuales se ha reportado interesantes singularidades, principalmente en la hialuronidasa de $B$. atrox, especie responsable de la mayoría de casos de ofidismo del país. En el 2013, Gonzáles et al. ${ }^{7}$, reportaron una enzima de $110 \mathrm{kDa}$, una masa atípica para las hialuronidasas eucariotas, asimismo una estabilidad enzimática hasta las 100 horas y un pH óptimo de 5,0. No obstante, algunas características importantes como su dependencia a iones y su efecto difusor en modelos biológicos, no se han descrito. 
El presente trabajo busca incrementar el conocimiento acerca de las características bioquímicas y biológicas de la hialuronidasa y sentar los primeros estudios moleculares de esta enzima, que permitan dar respuesta a las características singulares antes mencionadas, con miras a explorar el modo de neutralizarla durante el envenenamiento.

\section{PARTE EXPERIMENTAL}

\section{Material biológico}

Veneno.- Se utilizó el veneno extraído de ejemplares adultos de Bothrops atrox procedentes de Pucallpa-Ucayali, y mantenidos en el serpentario "Oswaldo Meneses" del Museo de Historia Natural de la Universidad Nacional Mayor de San Marcos.

Antivenenos.- Para el ensayo de inmunodifusión se empleó el suero anti-botrópico polivalente comercial del Instituto Nacional de Salud (INS) Lima-Perú.

Animales de experimentación.- Se emplearon ratones albinos Balb-c machos (18-22g) procedentes del bioterio del INS-Perú. El cuidado animal fue hecho de acuerdo con las recomendaciones éticas de la Biomedical Research Involving Animals of the Council of International Organizations of Medial Sciences (COIMS).

\section{Enzima purificada}

La hialuronidasa del presente estudio se obtuvo según el método desarrollado por González et $a .^{7}$, que emplearon dos pasos cromatográficos, uno de intercambio aniónico sobre DEAE Sephadex A-50 seguido de una columna de filtración molecular en Sephadex G-50.

\section{Cuantificación de proteína}

El contenido proteico del veneno y la enzima purificada fueron cuantificados midiendo la absorbancia de luz UV a $280 \mathrm{~nm}$ en un espectrofotómetro Shimadzu UV 120. Además, se empleó el método de Lowry, utilizando el reactivo de Folin Ciocalteu 1:6 en medio alcalino en presencia de albúmina sérica bovina como proteína estándar, midiéndose la absorbancia a $660 \mathrm{~nm}$.

\section{Actividad enzimática}

Fue llevada a cabo por el método turbidimétrico de Di-Ferrante ${ }^{10}$. La mezcla de reacción contenía $0,2 \mathrm{~mL}$ de ácido hialurónico $(0,5 \mathrm{mg} / \mathrm{mL}), 0,25 \mathrm{~mL}$ de buffer acetato de amonio $0,05 \mathrm{M}$ a pH 5,0 con $\mathrm{NaCl} 0,15 \mathrm{M}$ y se adicionó $0,05 \mathrm{~mL}$ del veneno $(1 \mathrm{mg} / \mathrm{mL})$ o enzima purificada $(0,1 \mathrm{mg} / \mathrm{mL})$. Luego se incubó a $37^{\circ} \mathrm{C}$ por 15 minutos, deteniéndose la reacción con $2 \mathrm{~mL}$ de bromuro cetil trimetil amonio (BCTA) al 2,5\% en $\mathrm{NaOH} 2 \%$. Finalmente, se midió la turbidez a $400 \mathrm{~nm}$. La actividad específica fue expresada en unidades Di-Ferrante (UDF) la cual se define como la cantidad de proteína requerida para reducir la turbidez inicial del sustrato en un $50 \%$. 


\section{Efecto de iones sobre la actividad enzimática}

Se prepararon baterías de reacción conteniendo: $\mathrm{KBr}, \mathrm{KCl}, \mathrm{NaCl}, \mathrm{CaCl}_{2}$ y $\mathrm{MgCl}_{2}$ en el rango de 0,05 a $0,3 \mathrm{M}$. Se preincubaron alícuotas de la enzima con los respectivos iones por 10 minutos a $37^{\circ} \mathrm{C}$ y luego se midió la actividad enzimática según el método antes descrito.

\section{Efecto de algunos aminoácidos sobre la actividad enzimática}

En estas pruebas se utilizaron ácido glutámico, glicina y el tripéptido glutatión preparados a concentraciones de 3, 6 y $12 \mathrm{mM}$. Las alícuotas de la enzima con el respectivo compuesto se preincubaron a $37^{\circ} \mathrm{C}$ por 10 minutos y luego se midió la actividad enzimática.

\section{Determinación de la toxicidad}

Se trabajó con cinco grupos de ratones albinos, a los cuales se les inoculó intraperitonealmente $0,1 \mathrm{~mL}$ de hialuronidasa $(5-20 \mu \mathrm{g})$. El control positivo se realizó con $0,1 \mathrm{~mL}$ de veneno crudo $(1 \mathrm{mg} / \mathrm{mL})$ y el control negativo con $0,1 \mathrm{~mL}$ de solución salina. Luego se monitoreó la mortalidad o reacciones adversas en los ratones en un lapso de 48 horas. Después de este tiempo, los ratones fueron sacrificados y sometidos a disección para observar daños cutáneos y/o viscerales.

\section{Evaluación del efecto difusor}

Fue realizado por medio de la actividad hemorrágica, de acuerdo con Isla et al. ${ }^{11}$. Se prepararon 5 muestras que fueron inoculadas vía intradérmica en ratones. La muestra 1 contenía 1,4 $\mu \mathrm{g}$ de veneno completo, equivalente a 1 dosis hemorrágica mínima (1 DHM), Segura et. al. ${ }^{11} \mathrm{La}$ muestra 2 contenía $1,4 \mu \mathrm{g}$ de veneno completo previamente inactivado por calor a $60{ }^{\circ} \mathrm{C}$, la muestra 3 contenía 1,4 $\mu \mathrm{g}$ de la enzima purificada, la muestra 4 contenía la mezcla de $1,4 \mu \mathrm{g}$ de veneno y enzima, respectivamente; finalmente, la muestra 5 contenía veneno inactivado por calor más la enzima $(1,4 \mu \mathrm{g} \mathrm{c} / \mathrm{u})$. Luego de dos horas de la inoculación, los animales fueron sacrificados y se les retiró la piel de la zona abdominal para observar el lado interno y calcular el diámetro y el área hemorrágica.

\section{Reconocimiento por el suero anti-botrópico}

Adicional al reporte de neutralización previo $^{7,12}$, se evaluó el grado de reconocimiento de la enzima por parte del suero anti-botrópico polivalente-INS, siguiendo el método de Ouchterlony y Nilsson. El veneno crudo y la enzima se analizaron por inmunodifusión contra el antiveneno. El revelado fue realizado con el colorante azul brillante de Coomasie al $0,1 \%$ y una solución decolorante para poder evidenciar las líneas de precipitación.

\section{Estudios moleculares}

El objetivo de este acápite fue el de obtener la secuencia de aminoácidos de la enzima a partir de la secuencia de nucleótidos codificantes, y determinar in silico las características bioquímicas de la proteína en estudio.

\section{Aislamiento de RNA y su conversión en cDNA}

Se realizó de acuerdo con el método descrito por Vivas et al. ${ }^{13}$, con el objetivo de no sacrificar a los animales. Las muestras de veneno fresco, obtenidas por presión manual, sobre las 
glándulas de ejemplares de Bothrops atrox, fueron recibidas en viales de 1,5 mL conteniendo RNA later con el fin de mantener integro la calidad de RNA total. Posteriormente, el RNA fue purificado empleando el kit de aislamiento High Pure (Roche) seguido de su conversión a cDNA con el kit Transcriptor First Strand cDNA Synthesis (NOVAGEN); para ambos casos se procedió de acuerdo con las instrucciones de los fabricantes.

\section{Diseño de cebadores}

La literatura determina que el tamaño del cDNA de las hialuronidasas oscila entre los 1500 y 2500 pares de bases (pb). Por esta razón, se realizó un alineamiento múltiple de las hialuronidasas de Protobothrops mucrosquamatus (GenBank: XM_015822281.1), Ovophis okinavensis (GenBank: AB851978.1), Protobothrops flavoviridis (Gen Bank: AB851937.1) y Bothrops neuwiedi pauloensis (GenBank: FJ654998.1), a partir del cual fueron diseñados manualmente 5 pares de cebadores (HD1- HDr10) y sintetizados por la casa comercial Invitrogen ${ }^{2}$.

\section{Obtención del cDNA de la hialuronidasa}

Para amplificación de la secuencia del gen se empleó el siguiente protocolo de amplificación: un ciclo de denaturación inicial $95^{\circ} \mathrm{C}$ por 5 min seguido por 32 ciclos de desnaturalización a $94^{\circ} \mathrm{C}$ durante 30 segundos; hibridación a $56-60^{\circ} \mathrm{C}$ por 30 segundos y una polimerización a $72^{\circ} \mathrm{C}$ por 80 segundos; finalmente, se incubó a $72^{\circ} \mathrm{C}$ por 7 minutos. Los productos amplificados fueron visualizados por electroforesis de agarosa al $1 \%$ preteñido con el intercalante RedGel. El secuenciamiento de los productos amplificados fue realizado en un secuenciador automatizado ABI 3730 XL realizado por la casa comercial Macrogen, Inc, Corea del Sur).

\section{Análisis in silico.}

La secuencia nucleotídica resultante fue sometida al análisis de identificación empleando el servidor en línea BLASTn (http://www.ncbi.nlm.nih.gov/gorf/gorf.html). El análisis de los marcos de lectura abierta (ORFs) y la traducción de la secuencia nucleotídica fue obtenida mediante los programas ORF finder (http:/www.ncbi.nlm.nih.gov/gorf/gorf. html) y Translate Tool (http://ca.expasy.org). La preferencia de codón (Codon Usage) fue realizado mediante el programa online SMS (http://www.bioinformatics. org/sms2/codon usage.html). La proteína deducida fue analizada tanto en identidad como en semejanza con otras secuencias de hialuronidasas con el programa en línea BLASTp. La predicción de las propiedades bioquímicas de la proteína deducida fue realizada mediante el programa Protparam (http://ca.expasy.org/tools/protparam.html), la determinación del péptido señal mediante el programa Signal P (http://www.cbs.dtu.dk/ services/SignalP/) y los sitios potenciales de glicosilación fueron predichos con el software NetNGlyc (http://www.cbs. dtu. $\mathrm{dk} /$ services/NetNGlyc/). 


\section{RESULTADOS Y DISCUSIÓN}

\section{Efecto de iones y aminoácidos sobre la hialuronidasa de $B$. atrox.}

Los ensayos con iones $\mathrm{Na}^{+}, \mathrm{K}^{+}, \mathrm{Br}, \mathrm{Cl}^{-}, \mathrm{Ca}^{+2} \mathrm{y} \mathrm{Mg}^{+2}$ señalaron un grado distinto de inhibición o activación según la concentración utilizada. Los resultados obtenidos al preincubar la enzima con los iones a concentraciones finales $(50-300 \mathrm{mM})$, establecen que el ion $\mathrm{Mg}^{+2}$ $(150 \mathrm{mM})$ incrementa la actividad enzimática en $40 \%$ mientras que, el $\mathrm{Ca}^{+2}(150 \mathrm{mM})$ y el $\mathrm{K}^{+}(300 \mathrm{mM})$ incrementaron la actividad en $7 \%$ y $10 \%$, respectivamente (tabla 1$)$.

Tabla 1. Acción de los iones sobre la actividad enzimática.

\begin{tabular}{ccccc}
\hline & \multicolumn{2}{c}{ \% Actividad enzimática (UDF/ mg) } & \multicolumn{2}{c}{ (Enzima purificada $=\mathbf{1 0 0} \mathbf{\%})$} \\
Agentes & $\mathbf{5 0} \mathbf{~ m M}$ & $\mathbf{1 0 0} \mathbf{~ m M}$ & $\mathbf{1 5 0} \mathbf{~ m M}$ & $\mathbf{3 0 0} \mathbf{~ m M}$ \\
\hline $\mathbf{M g C l}_{\mathbf{2}}$ & 90 & 115 & 140 & 105 \\
$\mathbf{K B r}$ & 80 & 90 & 95 & 110 \\
$\mathbf{C a C l}_{\mathbf{2}}$ & 70 & 88 & 107 & 86 \\
$\mathbf{N a C l}$ & 78 & 94 & 99 & 84 \\
$\mathbf{K C l}$ & 65 & 83 & 93 & 78 \\
\hline
\end{tabular}

Existen numerosos estudios que demuestran la influencia de los cationes divalentes en la actividad de las enzimas de origen ofídico. Algunos de ellos han mostrado que los aniones monovalentes $\mathrm{Cl}^{-}$y $\mathrm{Br}$ elevan la actividad de la enzima purificada como en el caso del veneno de L. $m u t a^{8}$. En nuestro caso se verificó que el ion $\mathrm{Mg}^{+2}$ un típico activador enzimático en las ponzoñas de serpientes tiene acción sobre hialuronidasa de $B$. atrox, en este caso también se observó semejanza con $B$. brazili ${ }^{9}$ ya que el $\mathrm{Mg}^{+2}$ también incrementaba su actividad. Aun cuando en este estudio no se hizo el análisis de iones divalentes asociados a la estructura enzimática, no existe ningún reporte hasta la fecha sobre la presencia del ion $\mathrm{Mg}^{+2}$ como cofactor de la hialuronidasa.

Por otra parte, en varias enzimas ofídicas, se ha demostrado la influencia de los L-aminoácidos en el incremento o reducción de la actividad específica. La glicina tuvo efecto inhibidor al reducir la actividad en 39 y $44 \%$ a las concentraciones de $6 \mathrm{mM}$ y $12 \mathrm{mM}$, respectivamente. Por otro lado, el ácido glutámico, así como el glutatión mostraron valores de inhibición menores al $20 \%$ (tabla 2). Para el caso de la glicina, este aminoácido puede estar trabando el acceso del sustrato al sitio activo u obstruyendo a los residuos involucrados. De hecho, la glicina que es un zwitterion $(\mathrm{pI}=5,97)$ tiene la capacidad de interactuar con la proteína a través de sus grupos cargados negativa y positivamente, y debido a su tamaño pequeño no es impedido estéricamente de unión débil a múltiples partes de la proteína ${ }^{15}$. 
Tabla 2. Efecto de aminoácidos sobre la actividad de la hialuronidasa.

\begin{tabular}{|c|c|c|c|}
\hline \multirow[b]{3}{*}{ Concentraciones } & \multicolumn{3}{|c|}{$\%$ de Inhibición de la Actividad Enzimática } \\
\hline & \multicolumn{3}{|c|}{ Aminoácidos } \\
\hline & Glicina & Glutatión & Ac. Glutámico \\
\hline $3 \mathrm{mM}$ & 33 & 19.5 & 9 \\
\hline $6 \mathrm{mM}$ & 39 & 18.5 & 17 \\
\hline $12 \mathrm{mM}$ & 44 & 17.7 & 19 \\
\hline
\end{tabular}

\section{Análisis de la toxicidad, capacidad difusora y reactividad antigénica de la enzima} La enzima no produjo daño alguno al ser inyectado intraperitonealmente; con ello se demuestra que carece de toxicidad, lo cual también ha sido reportado para las hialuronidasas de Agkistrodon contortrix contortrix ${ }^{4}$, Agkistrodon acutus acutus ${ }^{5}$, Lachesis muta $^{8}$ y B. brazili ${ }^{9}$ entre otros venenos.

Para comprobar la acción difusora de la hialuronidasa se usó como parámetro la actividad hemorrágica que posee el veneno de $B$. atrox (Foto 1 ). De acuerdo con ello, 1,4 $\mu$ g de veneno produce un área hemorrágica de $10 \mathrm{~mm}^{11}$. Cuando el veneno fue calentado a $60{ }^{\circ} \mathrm{C}$ el área hemorrágica se redujo a $2,5 \mathrm{~mm}$ en comparación al control positivo. La enzima purificada no produjo ninguna área hemorrágica, no obstante, amplió el área hemorrágica del veneno crudo a 12,8 mm. Por último, el veneno calentado mezclado con la enzima activa originó una área hemorrágica de $3,7 \mathrm{~mm}$. Estos resultados muestran concordancia con la prueba de difusión mediante hemolisis en placas ${ }^{8}$ ya que, en ambas, se monitoreo el efecto difusor de la hialuronidasa.

Adicionalmente, la prueba de inmunodifusión permitió establecer la antigenicidad de la enzima cuya reactividad se evidencia frente al antiveneno botrópico polivalente ya que se forma una línea de precipitina bien definida; el veneno crudo, enfrentado al mismo antiveneno produjo al menos 5 líneas de precipitación. Esta misma reactividad se ha visto en los estudios de esta enzima en $L$. muta $^{8}$ y B. brazili ${ }^{9}$.

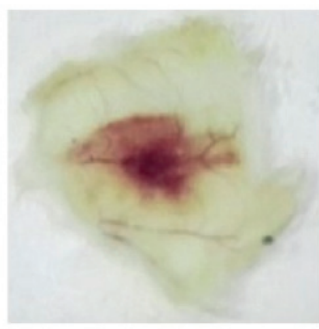

a)

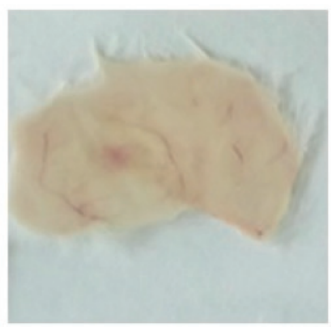

b)

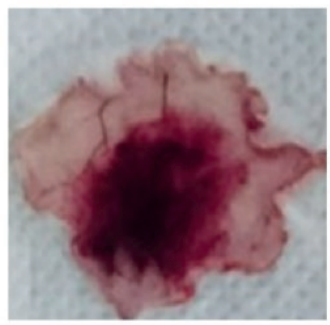

c)

Foto 1. Efecto difusor de la enzima purificada. Se evaluó por el incremento del área hemorrágica, causada por el veneno total en comparación con el área obtenida al adicionar la enzima purificada. Hemorragia producida por el veneno total b) ausencia de hemorragia al inocular la enzima purificada c) hemorragia producida por el veneno total más la enzima purificada. 


\section{Amplificación y secuenciamiento de la secuencia nucleotídica}

A partir de $400 \mu \mathrm{L}$ de veneno fresco obtenido por presión manual a un ejemplar de Bothrops atrox se obtuvo $40 \mu \mathrm{L}$ de RNA total, con ello se procedió a su conversión en cDNA el cual fue utilizado para amplificar el gen de interés.

Los cebadores diseñados, en dirección 5' $\rightarrow$ 3', fueron: HD1: ctccegcggatgttactcgtgg, HD2: atttggaaggtcgttcttctca, HD3: ataaatcaaaatcggatattga, HDr4: ccagttttcccagtcaatgact, HD5: tgaaaccatattgaggtcaagt, HD6: attgggacgttatatcgttaat, HDr7: cacatcttccacgtttcttgca, HDr8: ccagttttccttttacaatcac, HDr10: ttccttaatttttaattacagc. El posicionamiento de estos cebadores dentro de la secuencia consenso se muestran en la figura 1. Los amplicones obtenidos fueron visualizados mediante electroforesis en gel de agarosa al $1 \%$ y preparados para su secuenciamiento.

El ensamblaje de los segmentos obtenidos permitió la identificación de una secuencia constituida por 2020 pares de bases, la cual fue depositada en la base de datos del GenBank del NCBI con código de acceso KY499627, el análisis por BLASTn, evidenció una notoria homología con otras secuencias pertenecientes a hialuronidasas de origen ofídico depositadas en la base de datos, siendo la más homóloga la hialuronidasa de Protobothrops mucrosquamatus (GenBank: XM_015822281) con una identidad del $95 \%$ y una longitud de cobertura del $98 \%$.

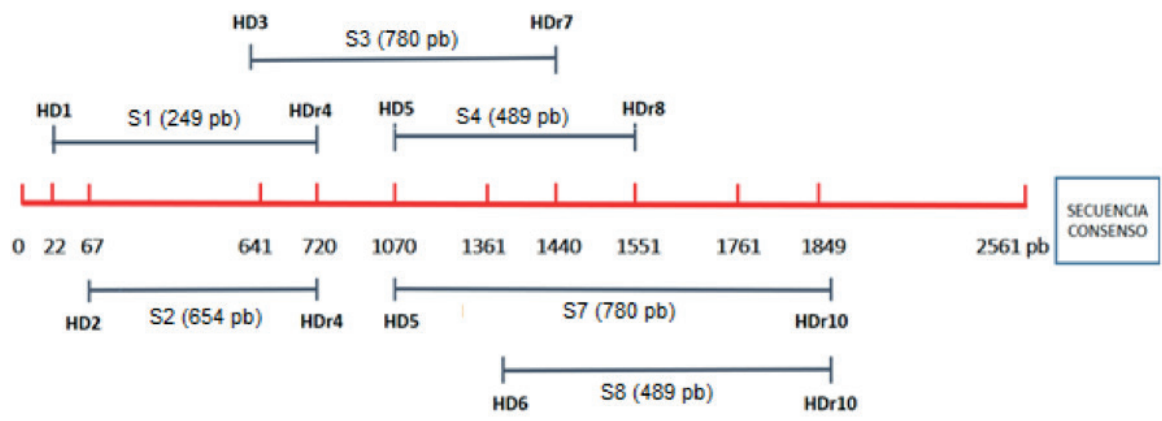

Figura 1. Segmentos de la secuencia consenso para la obtención del gen de la hialuronidasa de $B$. atrox.

\section{Obtención de la secuencia aminoacídica}

El análisis con el Programa ORF finder dio un marco de lectura +1 , con búsqueda limitada al codón de iniciación ATG, para una secuencia proteica de 449 aminoácidos, corroborado con el programa Translate Tool. La proteína deducida (figura 2) se enmarca a partir del nucleótido 178 hasta el nucleótido 1350 con el codón stop TAA determinándose una región nucleotídica no traducida 5' (UTR 5') de 177 pb y una UTR 3' de 669 pb.

El programa Signal P predijo un péptido señal de 20 aminoácidos en la posición N-terminal (figura 2), los 429 aminoácidos restantes, conforman la proteína madura que al ser analizada con el programa BLASTp determina homología con otras hialuronidasas, siendo 
la hialuronidasa de Bothrops moojeni (ATU85542) la de mayor identidad (98 \%) con una longitud de cobertura del 100 \%. La secuencia proteica de Bothrops atrox, producida en el presente estudio, fue denominada como Ba-Hyal y también se encuentra depositada en la base de datos con el código de acceso AUF71538.

Por otro lado, el análisis de la secuencia primaria con el programa ProtParam deduce una masa molecular de $50.10 \mathrm{kDa}$ con un pI. teórico de 9.19 estableciéndose la naturaleza básica de esta enzima. Se obtuvo un total de 6994 átomos. El coeficiente de extensión molecular fue de $88405 \mathrm{M}^{-1} \mathrm{~cm}^{-1}$ y un índice alifático de 76.15 .

La composición de los aminoácidos de la proteína madura mostró que el aminoácido más abundante fue la leucina ( 37 residuos, $8,6 \%$ ) en tanto que la cisteína y el triptófano fueron los menos abundantes (ambos con 10 residuos, 2,3\%).

Asimismo, mediante el programa NetGlyc fueron identificados 6 motivos de N-glicosilación (Asn-X-Ser/Thr). No obstante, sólo cuatro de los residuos en las posiciones Asn ${ }^{103}$, Asn ${ }^{111}$, $\mathrm{Asn}^{153} \mathrm{y} \mathrm{Asn}^{357}$ resultaron con un mayor score.

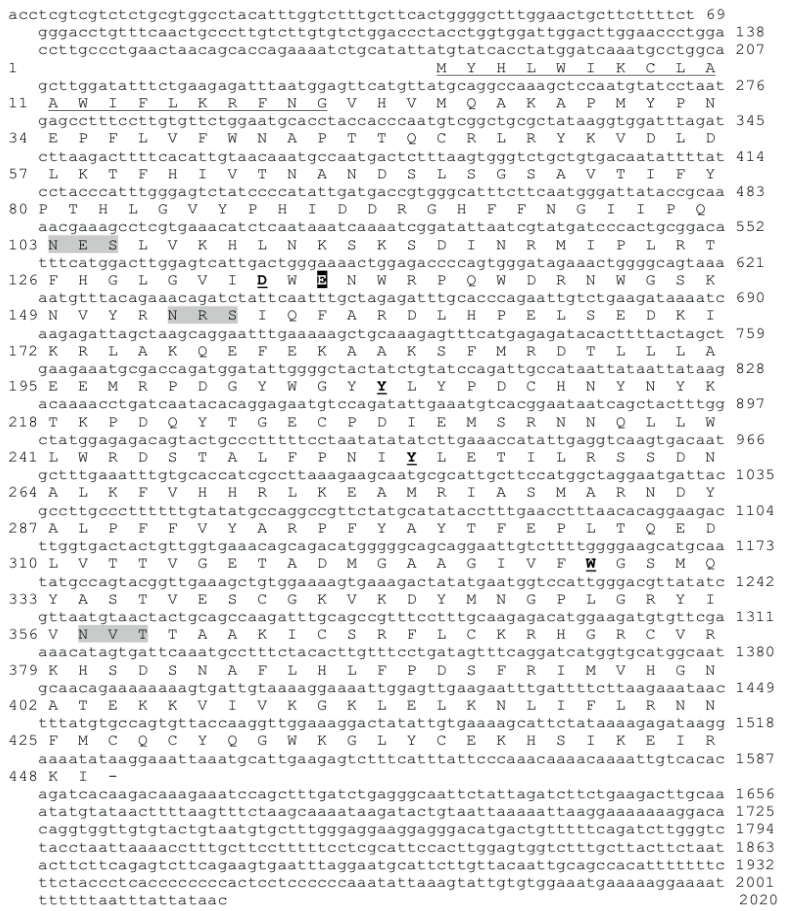

Figura 2. Secuencia nucleotídica y secuencia de aminoácidos inferida de la hialuronidasa de $B$. atrox. Los numerales a la derecha e izquierda de la figura se refieren las secuencias de nucleótidos y de aminoácido, respectivamente. El residuo catalítico conservado $\left(\mathrm{E}^{135}\right)$ los residuos posicionales $\left(\mathrm{D}^{133}\right.$, $\mathrm{Y}^{206}, \mathrm{Y}^{253}, \mathrm{~W}^{328}$ ) de las hialuronidasas de los vertebrados son identificados en cuadros y subrayados, respectivamente. La terminación del ORF por el codón TAA es indicado por un guion. Los cuatro principales motivos de $\mathrm{N}$-glicosilación están sombreados $\left(\mathrm{N}^{103} \mathrm{~N}^{111} \mathrm{~N}^{153} \mathrm{~N}^{357}\right)$. 
El estudio realizado por Harrison et al. ${ }^{16}$, basado en secuencias de cDNA de la glándula del veneno de Echis ocellatus, constituye la primera secuencia completa de una hialuronidasa del veneno de serpiente. La enzima de esta serpiente tiene cinco sitios de N-glicosilación conservados, tres de los cuales parecían tener alto potencial de glicosilación, esta enzima tiene una alta homología del $95 \%$ con las hialuronidasas de los venenos de Echis pyramidum leakeyi, Bitis arietans y Cerastes cerastes cerastes. Cada uno de ellos ha conservado los residuos de la región catalítica (Glu135), las regiones posicionales (Asp133, Tyr206, Tyr253 y Trp328) y los scaffold de cisteínas (Cys340, Cys211, Cys227, Cys365, Cys370, Cys376 y Cys429). En nuestro caso la hialuronidasa de B. atrox también tiene como región catalítica (Glu135) y las mismas regiones posicionales observándose una alta homología a nivel molecular con las enzimas mencionadas.

La comparación de los datos moleculares presentados en este estudio, con respecto a los datos bioquímicos reportados por González et al. ${ }^{7}$, determinan una significativa diferencia en el peso molecular, $50 \mathrm{kDa}$ vs $110 \mathrm{kDa}$. Esta diferencia podría ser explicada por la presencia de glicosilaciones, ya que las hialuronidasas presentan grados de glicosilación que oscilan entre el 10 - $30 \%$ y se ha demostrado la presencia de motivos de N-glicosilación en la secuencia de esta proteína; los estudios de deglicosilación nos darán información sobre los impactos de glicosilación en la masa molecular de la enzima. También se puede hipotetizar dos razones fundamentales para estas diferencias en peso molecular: la primera es que puede tratarse de una isoforma dimérica per se, pero los datos de González et al. ${ }^{7}$, indican que el $2 \beta$ mercaptoetanol no tiene efecto significativo sobre la actividad, no obstante, estudios con agentes reductores más fuertes como el DTT pueden dar más luces al respecto. La segunda opción sería una dimerización en solución, a un $\mathrm{pH}$ ácido los residuos de metionina y cisteína (con radical expuesto) tienden a oxidarse y promover la dimerización, por lo que el análisis de espectrometría de masas podría explicar este comportamiento.

Las expectativas que han abierto los estudios moleculares son muchas, especialmente en el entendimiento de la estructura y los mecanismos de acción de la enzima hialuronidasa de Bothrops atrox en el proceso de envenenamiento para de esta forma, poder diseñar una mejor estrategia de neutralización de los componentes tóxicos de dicha ponzoña.

\section{CONCLUSIONES}

Los resultados del presente trabajo corroboran la presencia de la enzima hialuronidasa de la serpiente peruana Bothrops atrox y su rol difusor de los componentes tóxicos del veneno. Los análisis moleculares in silico determinan un peso de $50 \mathrm{kDa}$ con un pI 9.19, lo que indica la presencia de modificaciones postraduccionales como las glicosilaciones o una posible versión dimérica de la proteína. Este singular hecho abre nuevas expectativas para el estudio de esta enzima. Asimismo, la enzima es activada por el ion magnesio e inhibida por el aminoácido glicina y es reconocida por el suero antibotrópico polivalente (INS-Perú). 


\section{AGRADECIMIENTOS}

Los autores de este artículo agradecen el financiamiento a Innóvate Perú, Proyecto Contrato N¹31-FINCyT-IB-2013 "Producción de antivenenos específicos contra serpientes peruanas empleando tecnología IgY”. El presente trabajo fue parte de la tesis de Maestría en Biología Molecular del autor principal.

\section{REFERENCIAS BIBLIOGRÁFICAS}

1. Menzel EJ, Farr C. Hyaluronidase and its substrate hyaluronan: biochemistry, biological activities and therapeutic uses. Cancer Lett. 1998; 131:3-11.

2. Stern R. Hyaluronan catabolism: a new metabolic pathway. Eur J Cell Biol. 2004; 83, 317-325.

3. Meyer K. Hyaluronidases In: Boyer, P.D. (Ed.). The enzymes. New York: Academic press; 1971. pp: 307-320.

4. Kudo K, Tu AT. Characterization of hyaluronidase isolated from Agkistrodon contortrix contortrix (Southern Copperhead) venom. Arch Biochem Biophys. 2001; 386: 154-162.

5. Xu X, Wang X, Liu X, Huang J, Lu Z. Purification and partial characterization of hyaluronidase from five pace snake (Agkistrodon acutus) venom. Toxicon. 1982; 20: 973-981.

6. Girish KS, Kemparaju K. A low molecular weight isoform of hyaluronidase: Purification from Indian cobra (Naja naja) venom and partial characterization. Biochem (Mosc.) 2005; 70:708-712.

7. Hurtado L, Lerma L, Rodriguez E y Yarlequé A. Evaluación Aislamiento y algunas propiedades bioquímicas de una hialuronato glucanohidrolasa del veneno de la serpiente Peruana Lachesis muta "shushupe”. Rev Soc Quim Perú. 2007; 73(4): 226-234.

8. González E, Ortiz C, Sandoval G, Lazo F, Delgadillo J, Rodríguez E, Severino R, Yarlequé A. Purificación y caracterización bioquímica de un factor de difusión presente en el veneno de la serpiente Bothrops atrox “jergón”. Rev Soc Quim Perú. 2013; 79(1): 3-12.

9. Delgadillo J, Palomino M, Lazo F, Rodríguez E, González E, Severino R, et al. Purificación y algunas propiedades de una hialuronidasa de la serpiente Bothrops brazili “jergon shuhuspe”. Rev Soc Quim Perú. 2013; 79(4):348-358.

10. Di Ferrante N. Turbidimetric measurement of acid mucopolysaccharides and hyaluronidase activity. Med Res. 1955; 303-306.

11. Isla M, Málaga $\mathrm{O}$, Yarlequé $\mathrm{A}$. Características bioquímicas y acción biológica de una hemorragina del veneno de Bothrops brazili. An Fac Med. 2003; 64(3): 159-166.

12. Segura A, Castillo MC, Núñez V, Yarlequé A, Gonçalves LR, Villalta M, et al. Preclinical assessment of the neutralizing capacity of antivenoms produced in six Latin American countries against medical - relevant Bothrops snake venoms. Toxicon. 2010; 56(6):980-9.

13. Vivas-Ruiz D, Sandoval G, Mendoza J, Inga RR, Gontijo S, Richardson M, Eble JA, Yarleque A, Sánchez EF. Coagulant thrombin-like enzyme (barnettobin) from Bothrops barnetti venom: molecular sequence analysis of its cDNA and biochemical properties. Biochimie. 2013; 95(7):1476-86. doi: 10.1016/j.biochi.2013.03.015. 
14. Cevallos M, Navarro Duque C, Varela-Julia M, Alagon C. Molecular mass determination and assay of venom hyaluronidases by sodium dodecyl sulfate- polyacrilamide gel electrophoresis. Toxicon 1992; 30: 925-930.

15. Jaworek MW, Schuabb V, Winter R. The effects of glycine, TMAO and osmolyte mixtures on the pressure dependent enzymatic activity of $\alpha$-chymotrypsin. Phys Chem Chem Phys. 2018 Jan 17; 20(3):1347-1354. doi: 10.1039/c7cp06042d.

16. Harrison R, Ibson F, Wilbraham D, Wagstaff S. Identification of cDNAs encoding viper venom hyaluronidases: Cross- generic sequence conservation of full length and unusually short variant transcripts. Gene. 2007; 392: 22-33. 